Neste artigo, pensa-se a articulaçâo psicanálise/educação a partir do modo como a educação - entendida como processo de transmissão de marcas simbólicas geradoras de efeitos de subjetivação - está presente na clínica psicanalítica de crianças autistas e psicóticas. Para tanto, pensa-se a questão da interpretação em função da relação com o Outro tal como esta se dá no autismo e nas psicoses.

Autismo; psicoses infantis; clínica psicanalítica; educação

\section{CLINIC FOR THE} AUTISM AND CHILD PSYCHOSIS OR HOW TO CONCEIVE THE ARTICULATION PSYCHOANALYSIS / EDUCATION IN THE TREATMENT OF THE "OBJECT-CHILDREN"

In this article, the articulation of psychoanalysis / education is thought from the way like education - understood as the process of symbolic marks, which generates subjectivistic effects - is present in the psychoanalytic clinic for autistics and psychotic children. For such, the subject of the interpretation is thought in relation to the contact with the Other, in the way it happens in the autism and in psychosis.

Autism; child psychosis; psychoanalytic clinic; education

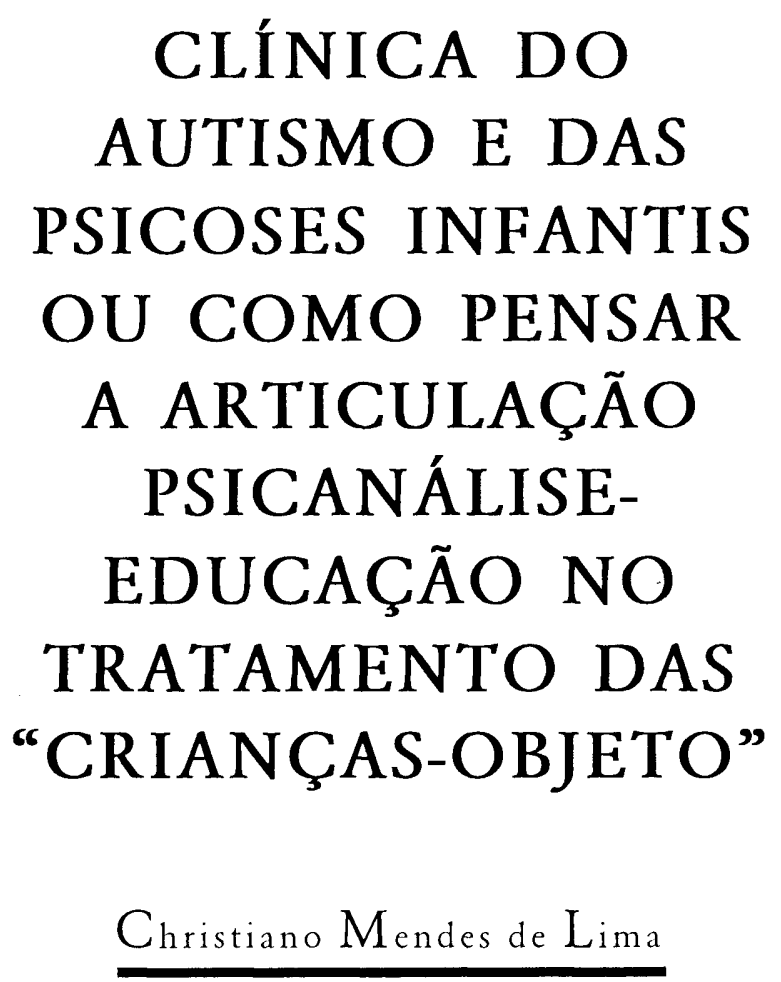

INTRODUÇÃO

(Dabemos que Freud foi de início bastante otimista no que se refere à articulação da psicanálise com a educação, depositando em uma educação esclarecida pela psicanálise esperanças de se prevenir as neuroses. $\mathrm{Na}$ introdução que escreve para o livro de Pfister, Freud afirma textualmente: "A educação constitui uma profilaxia, que se destina a prevenir ambos os resultados - tanto a neurose quanto a perversão (...)" (Freud, 1913, p. 416). A seguir afırma que o educador, de posse do conhecimento for-

Psicólogo clínico, membro da Clínica Freudiana de Uberlândia, psicólogo do NAPS Infantil da Prefeitura Municipal de Uberlândia, mestrando da Faculdade de Educação da USP. 


\section{Dossiê}

necido pela psicanálise, "poderia detectar as primeiras indicações de um desenvolvimento na direção da neurose e resguardar a criança contra o seu desenvolvimento ulterior (...)" (Freud, 1913, p. 416). Porém, com o desenvolvimento de sua obra, acaba por considerar que há uma radical impossibilidade de a psicanálise fornecer qualquer sustentação para uma prática pedagógica. Isto se deve à própria natureza das descobertas da psicanálise. Por exemplo, temos de considerar que entre educador e educando há o inconsciente de um e de outro, e que este não pode ser controlado por nenhum método pedagógico. Ingenuamente também poderíamos pensar que o papel do educador psicanaliticamente correto seria o de promover o processo de sublimação das pulsões parciais de seus alunos, porém, não se pode promover sublimação, já que esta é um processo inconsciente. Os exemplos poderiam se multiplicar.

Millot, em seu livro Freud antipedagogo, sustenta a completa disjunção dos campos da psicanálise e da educação, respondendo no desenrolar de sua argumentação com um rotundo não a três perguntas que coloca logo de início: 1) a psicanálise não pode fornecer as bases para uma educação que fosse capaz de prevenir as neuroses; 2) não se pode "conceber uma pedagogia 'analítica', no sentido de que teria os mesmos fins que a cura analítica - resolução do complexo de Édipo e superação do "rochedo da castração"” (Millot, 1992, p. 8); e 3) não se pode ter como base o método analítico para nortear a relação pedagógica.

Kupfer (2000) afirma que as conclusões de Millot não podem ser consideradas imprecisas ou errôneas, porém, devem ser matizadas, especialmente no tocante à sua segunda afirmação (veremos como isto pode ser feito). Quanto à primeira afirmação de Millot, há condições de se dizer que de fato não há como prevenir as neuroses pela educação, pois "delas não se escapa, porque são o fundamento de nossa subjetivação” (Kupfer, 2000, p. 14). Quanto à última, basta imaginarmos o ridículo da cena em que um professor pedisse a seus alunos para associar livremente.

Voltemos à segunda afirmação de Millot: não se pode "conceber uma pedagogia 'analítica', no sentido de que teria os mesmos fins que a cura analítica - resolução do complexo de Édipo e superação do 'rochedo da castração"' (Millot, 1992, p. 8). Aqui devemos ser mais cuidadosos. Cabe destacar, como afirma Kupfer (2000), que a cura analítica está sendo concebida a partir da ótica fornecida pelo tratamento das neuroses, pois só faz sentido falarmos em superação do Édipo e da castração no registro das neuroses. Mas o que dizer do tratamento de crianças que se viram impossibilitadas de viver o Édipo e a castração? Falamos das crianças psicóticas e autistas. Será que aqui também se mantém a completa 
disjunção entre os campos psicanalítico e educacional?

Sustentamos que há completa disjunção entre a psicanálise e a pedagogia, pois a pedagogia pode ser definida como "a busca de um 'saber positivo sobre como ajustar meios de ação e fins existenciais estabelecidos a priori" (Lajonquière citado por Kupfer, 2000, p. 23). É evidente que a descoberta do inconsciente lança ao chão qualquer pretensão pedagógica de controlar o processo de ensino-aprendizagem, pois o que o inconsciente revela é da ordem da ruptura, do imprevisto. Sabemos, e a experiência analítica é pródiga em exemplos, que mesmo em uma psicanálise o método serve para criar condições de emergência do inconsciente, e não para controlar o sujeito: não sabemos a priori que efeito terá uma interpretação, não sabemos de antemão se tocará a posição inconsciente do sujeito. Todo efeito só pode ser lido a posteriori, não há previsão possível, não há certeza, não há saber teórico ou método que controle as manifestações do inconsciente, nem dentro da prática psicanalítica nem na relação pedagógica.

Por outro lado, a psicanálise pode ser articulada à educação, se a entendermos como processo de transmissão de marcas simbólicas, geradoras de efeitos de subjetivação. Esta concepção de educação pode ser percebida claramente na educação primordial, em que o Outro parental opera no sentido de inscrever simbolicamente o Real do corpo e das vivências do infans. São estas marcas do Outro no sujeito que possibilitam o processo de subjetivação. $O$ 
autismo e as psicoses infantis podem ser entendidos como efeitos da falência deste processo, e, portanto, esta concepção de educação está intimamente ligada e presente na clínica psicanalítica do autismo e das psicoses infantis. Antes de mostrarmos como isto se dá, precisamos esclarecer como entendemos estas formas de estruturação psíquica sem sujeito.

\section{CRIANCCAS AUTISTAS E PSICÓTICAS: SUA RELAÇÃO COM O OUTRO E ALGUMAS CONSIDERACOÕES RELATIVAS À CLIINICA}

Para pensarmos o autismo temos de retornar ao tempo mítico que corresponde ao nascedouro do processo de subjetivação. Uma criança quando vem ao mundo depara com um universo simbólico que preexiste a ela. Todo o processo de subjetivação pode ser entendido como o modo de se articular, como afirma Calligaris (1986), dois campos heterogêneos: o real do corpo da çriança e o Simbólico (lugar da linguagem e do desejo que já está lá, no Outro). Freud (1914) afirma que o filho é o prolongamento do narcisismo parental, isto é, os pais veiculam em relação aos filhos uma série de desejos e demandas que se articulam na história dos desejos edipianos parentais. A subjetivação consiste em o filho poder se engan- char como objeto das demandas do Outro, entrando assim no campo da linguagem, o que possibilita a transformação de seu corpo biológico (organismo) em um corpo erógeno. Este processo que Lacan (1964) denomina de alienação é o primeiro tempo lógico necessário à constituição subjetiva do infans. Trata-se de a criança ter a possibilidade de banhar seu organismo nos significantes do desejo do Outro. Esta possibilidade pode ser abortada por uma infinidade de fatores que se articulam tanto do lado do Outro quanto do lado da criança. É evidente que o processo de subjetivação pode ser dificultado por patologias orgânicas (neurológicas e outras) que interfiram na capacidade da criança de estar no mundo, de estabelecer relações. Porém, a não ser em casos extremos, a simples deficiência orgânica não é suficiente para impedir o processo de subjetivação. Tudo vai depender de como o Outro significa tal intrusão do padecer orgânico no laço libidinal em que a criança é tomada. Por outro lado, crianças que nascem sadias, com todo o aparato neurológico necessário para se vincular ao campo do Outro, podem se ver impedidas de se alienar ao désejo do Outro simplesmente porque este desejo não visa a criança. Isto se articula, como já dissemos, às vicissitudes da constituição edípica dos próprios pais. Pode haver também uma interação destas duas séries de fatores como ilustra o discurso de uma mãe: o filho vinha se desenvolvendo normalmente, chegando até mesmo a articular as primeiras palavras, quando um processo infeccioso cerebral que resultou em coma e depois na perda das 
aquisições psicomotoras já feitas, bem como no desaparecimento da linguagem, pôs fim ao processo de subjetivação em andamento. Isto ocorreu não somente por causa da questão orgânica, mas principalmente porque o adoecimento lesou de modo radical o laço libidinal do Outro (encarnado no casal parental) com a criança. Impedidos de se reconhecer narcisicamente em seu filho, pois a distância entre o filho sonhado (narcisismo) e o estado atual do filho tornou-se sem fim, os pais não conseguiam mais supor nenhum sentido humano nos atos de seu filho, passando a vê-lo como um conjunto de neurônios que não funcionavam bem. Quando perguntada sobre seu filho, a mãe, por exemplo, só conseguia falar da lesão cerebral, dos exames, do tratamento que julgava necessário empreender com ele. Este tratamento era basicamente figurado como estimulação de feixes neuronais: a possibilidade de advir um sujeito na criança foi ceifada pelo dano no laço libidinal do Outro com a criança, que entra então em um quadro autístico claro (todas as descrições dos manuais médicos estando presentes). As estereotipias motoras, por exemplo, apareciam continuamente fixadas e impedidas de se significar pela ausência de sentido conferido pelo Outro: todos os comportamentos eram entendidos pelo Outro parental como produto da lesão cerebral.

Podemos definir o autismo, então, como uma impossibilidade de a criança entrar no campo da alienação ao desejo do Outro, pois o Outro não está lá, não pode investir 
libidinalmente a criança. Jerusalinsky (1993) descreve metaforicamente esta situação dizendo que "a mãe do autista coloca seu filho exatamente na mesma posição que o turista coloca o monumento na fotografia que ele mostrará a seus familiares no retorno de sua viagem. Ou seja, se fotografará de costas ao objeto que foi ver. A mãe do autista é uma turista do desejo. O objeto de seu desejo está fora de seu olhar" (Jerusalinsky, p. 65), ou seja, a criança não é visada pelo Desejo do Outro. Tal posição implica a impossibilidade de a criança ver perfilada sua imagem no olhar do Outro, impedindo a experiência chamada por Lacan (1949) de estádio do espelho, tempo em que se constitui o eu e todo o campo imaginário e simbólico necessário ao advento da subjetivação.

Jerusalinsky chama o mecanismo pelo qual o autista se relaciona com o campo do Outro de exclusão e afirma que esta posição implica a ausência de uma inscrição psíquica que a subjetive, acarretando efeitos específicos na relação com o Outro: "A ausência de uma inscrição coloca a criança, a respeito da demanda do Outro, a receber essa demanda na posição da repetição da exclusão. É por isso que o autista recebe qualquer manifestação do laço social, seja do modo direto ou indireto, como uma demanda de ausentificação. É por isso que a criança autista vira as costas àquele que a ela se dirige, ou se opõe especificamente a incorporar os objetos que lhe são oferecidos pelo outro" (Jerusalinsky, 1993, p. 64).

Quanto à psicose, Lacan afirma que sua questão estrutural situa-se precisamente na não ocorrência do segundo tempo (lógico) do processo de subjetivação: a operação de separação do infans do campo do Outro. Esta acontece na medida em que o Desejo do Outro orienta-se também para fora de sua relação com a criança, ou seja, há um terceiro em jogo: o pai simbólico suposto dar conta de satisfazer (ainda que parcialmente) as demandas e desejos do Outro "materno". Aqui está em jogo a castração simbólica que implica a retirada da criança da posição de objeto de Desejo do Outro e tem por efeito a inscrição do significante Nome-do-Pai no Inconsciente. Este significante organiza a relação do sujeito com o Outro, com o sexual e com o Real. Na psicose, como a castração simbólica não tem lugar devido à questão edípica do Outro parental, o psicótico permanece na posição de objeto, em uma relação sem mediação com o Desejo do Outro, que, não regulado pelo Nome-do-Pai, aparece a este como um gozo desmedido que tem por objeto seu ser. Exemplo lapidar está em "Notas psicanalíticas sobre um relato autobiográfico de um caso de paranóia", texto de Freud de 1911 mais conhecido como o Caso Schreber: Schreber acreditava-se objeto de manipulações cruéis e dolorosas, que culminariam em sua emasculação e posterior entrega de seu 
corpo para ser objeto do gozo lascivo do Outro. Assim, o Nome-doPai, ao se inscrever no Inconsciente a partir da castração simbólica, regula e ordena o funcionamento deste, pela mediação simbólica que estabelece entre o sujeito e o Desejo do Outro a partir do qual se constituiu, barrando o gozo avassalador do Outro.

Lacan (1955-6) faz a leitura de Freud, traduz o que este chamava de Verwerfung por "foraclusão" e eleva este termo à categoria de conceito para designar o mecanismo específico da psicose, ou seja, o que caracteriza a estrutura psicótica é a não ocorrência e, portanto, a não inscrição da castração no Inconsciente, no Outro. Assim, a psicose refere-se a uma estrutura em que o Nome-do-Pai encontra-se foracluído do Simbólico.

$\mathrm{O}$ que ocorre então nas psicoses infantis no que tange à relação $\mathrm{da}$ criança com a Demanda do Outro? Jerusalinsky afirma que, no caso da psicose, o mecanismo da foraclusão implica uma inscrição do sujeito, porém esta se dá em uma posição em que "não pode ter conseqüência na função significante (...). A criança psicótica recebe a demanda do Outro numa posição em que a inscrição produzida exige, para se manter, sua repetição no Real. É por isso que a criança psicótica responde com seu corpo à demanda do Outro sob a forma da agitação psicomotora, debatendo-se em hiperatividade, sob a forma do grito, ou demorando suas aquisições evolutivas no campo da motricidade" (Jerusalinsky, 1993, p. 63).

Do exposto, podemos afirmar que autismo e psicose, apesar de se tratar de quadros psicopatológicos distintos, podem ser considerados efeitos da falência de a educação primordial inscrever marcas simbólicas no psiquismo, o que acarreta impossibilidade de fundação do sujeito.

Como então conduzir uma clínica psicanalítica com crianças em que a função do sujeito não se constituiu?

Afirmamos: a clínica psicanalítica do autismo e das psicoses não é analitica, nem poderia ser. Não se trata de proceder à análise (desmontagem, decomposição) de um sujeito já constituído como é o caso da clínica das neuroses, em que devemos operar a desmontagem dos fantasmas, para que se revelem os significantes fundantes do sujeito e sua relação de alienação ao Desejo do Outro. No autismo e nas psicoses podemos considerar que se deve caminhar na direção contrária da análise das neuroses. Aqui se trata de construir, não de desconstruir. De acordo com Kupfer, Colette Soler diz que o tratamento do que chama de criançasobjeto (crianças em que a função do sujeito não está constituída, como é o caso do autismo e das psicoses) se faz na direção contrária da psicanálise clássica: "Se, na análise clássica, a operação analítica parte do Simbólico em direção ao Real, o que implica uma certa desconstrução desse Simbólico, na análise das 'criançasobjeto' a operação é a de permitir que se instale o Simbólico, e o ponto de partida é então o Real, esse contra o qual a criança não erigiu suas defesas" (Kupfer, 2000, p. 62). Trata-se então de uma prática clínica que caminha no sentido da educa- 
ção, conforme a definimos, ou seja, como o que possibilita a inscrição de marcas simbólicas, de significantes que possam servir de anteparo diante da invasão do Real.

Mas como isso pode se dar no quotidiano da clínica? Para respondermos a esta questão, vamos examinar o que ocorre com a interpretação na clínica do autismo e das psicoses.

Quando falamos de interpretação em psicanálise estamos nos referindo à formulação em palavras por parte do analista de um conteúdo latente que se faz representar distorcidamente em um conteúdo manifesto (relato de um sonho, por exemplo). Interpretar é então revelar o que se encontra velado pela operação do recalque. No autismo e nas psicoses não podemos falar na oposição conteúdo latente/conteúdo manifesto, justamente porque o recalque originário, operação que instaura a oposição consciente/inconsciente, não ocorreu. Interpretar, na clínica das crianças-objeto, não é então revelar, desvendar sentidos, justamente porque não há sentido a ser revelado.

$\mathrm{O}$ que é então? Para examinarmos o lugar da interpretação temos que considerar a relação com o Outro no autismo e nas psicoses.

Como já dissemos, a partir das formulações de Jerusalinsky (1993), a relação da criança autista com o Outro é de exclusão, pois diante de qualquer demanda do Outro a criança autista se apaga, torna-se ausente, fecha-se mais ainda. Estamos falando aqui dos quadros autísticos em que o fechamento é muito pronunciado. Nestes casos, a interpretação deve ser formulada com cuidado para não tomar a forma de uma demanda, pois isto poderia incrementar ainda mais o fechamento autístico. Mais uma consideração: como no autismo não há sujeito constituído, como não há propriamente o registro do inconsciente, como não há fantasias, a interpretação não caminha na direção da revelação de um sentido, mas na constituição deste.

Lacan dizia que um som só adquire o estatuto de mensagem se houver um Outro que o reconheça como tal, ou seja, a massa sonora, os vocalises só adquirem o sentido de mensagem (inscrevendo-se propriamente no registro do humano), se o Outro ouvi-los enquanto tal. A interpretação na clínica do autismo implica uma suposição de sujeito por parte do analista onde não há, para que daí possa advir.

Um exemplo: atendo uma criança de 3 anos que chegou com um quadro bastante significativo de desligamento do Outro (ausência do olhar, não resposta ao chamado da mãe, etc.). Este menino, que eu atendo com a mãe, ao final de toda sessão sai da sala e vai até o bebedouro beber água. Um dia, quase ao fim do tempo cronológico da sessão, vai até a porta, tenta abri-la, e não consegue. Então se dirige a mim, toma minha mão e a põe na porta. Não abro. Ele diz: "ag". Passados alguns segundos, tendo eu retirado a mão da porta, ele pega novamente minha mão e a põe na porta. Diz novamente: "ag". Volto-me para a mãe e pergunto: "O que ele está dizendo?" Mãe responde: "Nada não, são os barulhinhos que ele faz". 
Digo: "Acho que ele disse que quer água". Abro a porta, a criança vai direto ao bebedouro e bebe dois copos de água, sob o olhar estupefato da mãe, que me diz: "Nossa! Então ele fala? Não era só barulhinho, não?" Eu sorrio. Ela diz que anotará todos os barulhinhos dele, porque eu sei entendê-los. Vejamos: não importa se ele disse água ou não. O que importa é que o "barulhinho dele", simples massa sonora ao ouvido materno, pôde ser considerado mensagem a partir da minha interpretação, que não revela um sentido, mas constitui, engendra um sentido. Houve também uma mudança na posição subjetiva da mãe em ralação aos "barulhinhos" do filho, agora ela consegue perceber que deve haver um sentido nestes "barulhinhos". Supõe, por um efeito de sua transferência, que só eu sei o que estes barulhinhos querem dizer. Atualmente, ela mesma tem conseguido reconhecer e conferir sentido aos "barulhinhos" do filho. Em uma das últimas sessões, o filho pôs-se a repetir: "nenenenene". Ela então diz: "Ele tá falando nenê. É o nenê da mamãe”. O filho sorri. Eu também.

$\mathrm{Na}$ psicose, o Outro aparece à criança como onipotente, absoluto, não castrado, e a criança se situa (ou melhor, está situada) no Real como objeto de gozo deste Outro desmedido. Esta posição diante do Outro já a exemplificamos com Schreber e sua relação com Deus (Outro). Faremos brevemente uma diferenciação entre o modo como a relação com Deus, por exemplo, pode se dar na neurose e na psicose. Schreber respondia com o corpo à demanda que supunha em seu Outro (Deus), ou seja, respondia a esta demanda no Real, oferecendo seu corpo ao Outro. Imaginemos um neurótico e sua relação com Deus. O que ele oferece a Ele, a este Outro? Oferece orações, oferece promessas, oferece boas ações. É assim que responde ao que supõe que o Outro demanda dele, ou seja, oferece-se no plano simbólico para satisfazer esta demanda.

O que ocorre então na clínica da psicose? Como o psicótico responde à interpretação? A partir das características do Outro para o psicótico, as palavras do analista, quando formula uma interpretação, só podem ser tomadas enquanto fala de um Outro onipotente em relação à qual o psicótico se reduz a um objeto... de compreensão, de interpretação, etc. Um neurótico, quando formulamos uma interpretação para ele, dispõe de recursos que se articulam à dialética de sua relação com o Outro, pode denegá-la, por exemplo. Já o psicótico só pode tomá-la como um imperativo: "Na medida em que o Outro, na psicose, encontra-se não barrado, não castrado, toda interpretação vinda desse Outro assume caráter oracular, ou absoluto, algo assim como a voz de um Deus onipotente que faz a lei a seu favor, o que apenas reforça a posição objetal em que se encontra colocado o psicótico, além de fortalecer, em certos casos, uma posição paranóica” (Kupfer, 2000, p. 63).

Se a interpretação, pelas características do Outro na psicose, é contra-indicada, o que faz um analista no tratamento da psicose? Se não se deve interpretar na clínica da psico- 
se, é, no entanto, responsabilidade ética do analista intervir. Lacan (1955-6) situa a intervenção na clínica da psicose em um outro registro: "Sugere que o analista deva sobretudo prendre acte: registrar, acusar recebimento da mensagem de um paciente psicótico" (Kupfer, 2000, p. 64). $O$ analista, diz Lacan, deve-se fazer de "secretário do alienado". Este tipo de intervenção que consiste em marcar recebimento da mensagem, repetindo, por exemplo, o que o paciente disse, pode possibilitar que o mesmo se reconheça a posteriori como sujeito desta mensagem. Qualquer tentativa de compreensão, de interpretação significa fixar o psicótico no lugar de objeto, o que exclui a possibilidade de ele advir enquanto sujeito... da mensagem, do desejo.

Um exemplo: um menino de 7 anos que atendo recentemente descobriu a diferença sexual, ainda que não consiga saber de que lado está. Sempre pergunta se as pessoas têm "pipiu" ou "perereca". Ultimamente tem pedido que eu desenhe: "Desenha Maria" (sua mãe). Desenho. Ele diz: "Ela tem pipiu ou perereca?" Repito: "Pipiu ou perereca?" Ele: "Desenha a perereca dela". Desenho. Logo diz: "Desenha o Alexandre". Desenho. Ele diz: "Faz os óculos dele". Deserrho. Ele: "Faz o pipiu dele". Desenho.

Trata-se aqui de acompanhar o sujeito na elaboração da diferença sexual, e não de apor uma interpretação que poderia vir obstruir esta via de elaboração. Mês passado, mais ou menos na mesma época em que começou a se perguntar sobre "pipiu ou perereca”, sua mãe vem me pro- curar para contar que seu filho encontra-se com um medo atroz de trovões: chora, tampa os ouvidos, esconde-se debaixo da cama. Parecenos que assistimos à constituição de um sintoma fóbico. Mais uma vez não devemos interpretar, pois isto poderia contrariar a construção de um significante que o pudesse defender da demanda do Outro. Lacan nos diz que o significante fóbico é o que defende o sujeito quando este sente que pode ser tragado pela demanda do Outro. A função defensiva de seu sintoma fóbico aparece claramente nesta seqüência de seu tratamento: pede que eu desenhe um balão. Desenho. Ele diz: "Faz nuvem e trovão". Faço. "Desenha o Marcos" (Marcos é ele mesmo). Desenho. Então ele diz: "Trovão explode balão. Não deixa ele levar o Marcos".

Então, na clínica das criançasobjeto, o analista deve se situar enquanto Outro castrado, e não na posição de objeto a, como ocorre na clínica das neuroses, pois, como afirma Petri, se nos colocarmos "no lugar de objeto a para estas crianças, a clínica nos mostra que nada acontecerá. Dois objetos não fazem laço!" (Petri, 2000, p. 127). É da posição de Outro castrado que o analista pode acompanhar as construções de barreiras diante do gozo do Outro que a criança psicótica faz ao longo do tratamento. Não deve interpretar, não deve se situar em um lugar de saber, mas demonstrar fundamentalmente sua falta em saber, sua castração. Não deve pois se antecipar ao que a criança vai construindo, não deve desmontar as construções com interpretações, mas sim favorecer a 
construção de bordas simbólicas que a defendam do Real. Aqui psicanálise e educação se encontram, pois ambas tratam da construção de bordas simbólicas para o sujeito.

Um último exemplo para ilustrar a relação entre a educação e a clínica psicanalítica das crianças-objeto. Citado por Kupfer: um menino psicótico que começa a escrever. "Seu analista dedicou-se então a esse exercício com ele: punha-se a escrever o nome da criança, que por sua vez buscava, com todas as dificuldades de seu quadro, fazer alguns rabiscos que ele tomava como cópia de seu nome. Houve instantes em que a criança pedia ao analista que segurasse sua mão e a conduzisse no traçado das letras, colocando-o em uma cena típica de algum antigo mestre-escola com seu discípulo. A cada vez que o fazia, dizia 'escrever Antônio'. Certo dia, estava a mãe a contar sobre as dificuldades que Antônio tinha em aceitar suas saídas. Mencionou que era como se ele próprio não estivesse mais ali quando ela se ausentava. Antônio, como é seu costume nessas ocasiōes em que a mãe relata situações difíceis, agita-se, perambula pela sala. Mas desta vez dirigiu-se ao analista e the pediu: 'Escrever Antônio'. O analista o atendeu, e juntos escreveram seu nome. Ao final a criança disse: "Achou Antônio" (Kupfer, 2000, pp. 100-1). E a autora continua: "Nesse fragmento, assiste-se justamente à construção, através de seu rudimento de escrita, de uma borda para Antônio, que o faz surgir, achar-se, encontrar um ponto de ancoragem mínima. E o que fez o analista? Tratou ou ensinou? Tratou ensinando” (Kupfer, 1999, p. 101).

\section{REFERENCIAS BIBLIOGRÁFICAS}

Calligaris, C. (1986). A questio do tintasma na clínica psicanalítica (A. F. B. de Castro Dreyer e outros, trads.). Salvador, BA: Cooperativa Cultural Jacques Lacan.

Freud, S. (1911). Notas psicanalíticas sobre um relato autobiográfico de um caso de paranóia. In Edição standard brasileira das obras psicológicas completas de Sigmund_Freud (J. Salomão, trad.) (Vol. XII, pp. 23-108). Rio de Janeiro, RJ: Imago, 1990.

- (1913). Introdução a The psycho-analytic method, de Pfister. In Edifão standard brasileira das obras psicológicas completas de Sigmund Freud (J. Salomāo, trad.) (Vol. XII, pp. 415-8). Rio de Janeiro, RJ: Imago, 1990.

- (1914). Sobre o narcisismo: uma introdução. In Edição standard brasileira das obras psicológicas completas de Sigmund Freud (J. Salomão, trad.) (Vol. XIV, pp. 89-119). Rio de Janeiro, RJ: Imago, 1990. 
Jerusalinsky, A. (1993). Psicose e autismo na infância. Uma questão de linguagem. Boletim da Associação Psicanalítica de Porto Alegre, $\mathrm{n}^{\underline{a}} 9$.

Kupfer, M. C. M. (1999). A psicanálise na clínica da infância: o enfrentamento do educativo. In $A$ psicanálise $e$ os impasses da educação. São Paulo, SP: Lepsi-IP-USP/FE-USP.

---- (2000). Educação para o futuro. Psicanálise e educação. Sāo Paulo, SP: Escuta.

Lacan, J. (1949). O estádio do espelho como formador da função do eu tal como nos é revelada na experiência psi. canalítica. In Escritos (V. Ribeiro, trad.) (pp. 96-103). Rio de Janeiro, RJ: Jorge Zahar, 1998.

(1955-6). O seminário, livro 3, As psicoses (A. Menezes, trad.). Rio de Janeiro, RJ: Jorge Zahar, 1992.

(1957-8). O seminário, livro 5, As formaçōes do inconsciente (V. Ribeiro, trad.). Rio de Janeiro, RJ: Jorge Zahar, 1999.

_-_- (1964). O seminário, livro 11, Os quatro conceitos fundamentais da psicanálise (M. D. Magno, trad.). Rio de Janeiro, RJ: Jorge Zahar, 1995.

Millot, C. (1992). Freud antipedagogo (A. Roitman, trad.). Rio de Janeiro, RJ: Jorge Zahar.

Petri, R. (2000). O lugar do profissional no tratamento institucional da criança psicótica: analista ou educador. Dissertação de Mestrado, Instituto de Psicologia, Universidade de São Paulo, São Paulo, SP.

Recebido em abril/2001. 